\title{
Development of Mobile Health Application for Cardiovascular Disease Prevention
}

\author{
Vitri Tundjungsari ${ }^{1}$, Heri Yugaswara ${ }^{3}$, Adhika Trisna \\ Dwi Putra ${ }^{4}$ \\ Faculty of Information Technology \\ YARSI University \\ Jl. Letjen Suprapto, Jakarta, Indonesia
}

\author{
Abdul Salam M Sofro ${ }^{2}$ \\ Faculty of Medicine \\ YARSI University \\ J1. Letjen Suprapto, Jakarta, Indonesia
}

\begin{abstract}
Cardiovascular diseases are one of major cause of death in the world, as well as in Indonesia. In spite of that fact, cardiovascular diseases (CVDs) could be prevented with healthy behavior and lifestyle, such as: regular health check-up, healthy eating and drinking lifestyle, stress management, sleeping management, regular physical activities. In this paper, we develop mobile health application as a tool to record daily behavior and lifestyle. Mobile health is chosen because nowadays mobile devices are the most popular communication used among people. Thus, we believe that mobile Health (mHealth) is a promising tool to promote healthy lifestyle and behavior. The method we used for developing the application is called as Human-centered design (HCD). The application is evaluated iteratively from the first prototype (low-fidelity prototype) to the final prototype (high-fidelity prototype). Based on the feedback using User Experience Questionnaire (UEQ) shows that the application has above average scores for all of the components, i.e.: attractiveness, clarity, efficiency, accuracy and dependability, stimulation, and novelty. The best score is for Stimulation (Excellent), while the worst score is accuracy and dependability (above average). This shows that mHealth is a potential tool to stimulate users for having healthy lifestyle, however it still required further validation of use from health experts to ensure the accuracy's result of the application.
\end{abstract}

Keywords-Mobile health; cardiovascular; disease; humancentered design; standard; user-centered design

\section{INTRODUCTION}

Cardiovascular diseases (CVDs) are one of chronic diseases which cause highest mortality in the world (around $31 \%$ people died from CVDs which $85 \%$ of it died due to heart attack and stroke) [1]. WHO sheet fact [1] also mentions that over three quarters of CVD deaths are occurred in low and middle-income countries, including Indonesia. According to Indonesian basic health research report [2], cardiovascular diseases are the leading cause of death in Indonesia (31\%), which top two including hypertension and stroke.

WHO estimates that the number will increase until 2030, which estimated 23.6 million people will die from heart and blood vessel disease [1]. Cardiovascular diseases defined as a group of disorders of the heart and blood vessels, which include [1]:

- Coronary heart disease: disease caused by the blood vessels to provide blood for the heart muscle
- Cerebrovascular disease: disease caused by the blood vessels to provide blood for the brain

- Peripheral arterial disease: disease caused by the blood vessels to distribute blood supply in the arms and legs

- Rheumatic heart disease: disease caused by damage to the heart muscle and heart valves from streptococcal bacteria

- Congenital heart disease: disease caused by malformations of heart structure at birth

- Deep vein thrombosis and pulmonary embolism: disease caused by blood clots in the leg veins that able to dislocate and travel to the heart and lungs

Cardiovascular diseases can be prevented by having healthy behaviour and life style, such as: no smoking, avoid obesity, increase physical activities. Therefore it is important to foster such initiatives through mobile health (mHealth) application. Mobile application is a very promising tool to promote sustained and successful healthy behavioural lifestyle [3].

MHealth is also efficient and affordable tool to support and deliver information and education among people since almost individual in this world are having mobile communication, such as: smartphone and tablet $[4,5]$.

Based on the background above, we develop a mobile application as a tool to reduce and prevent cardiovascular risk by promoting healthy life style through mobile healthcare application. We believe that this research can provide an alternate tool to decrease cardiovascular disease prevalence in Indonesia, as well as to prevent it.

This paper consists of five main sections, i.e.: (1) introduction, (2) research related to mobile health application for CVDs management, (3) human-centered design method, (4) results and discussion, and (5) conclusion.

\section{Mobile HeAlth ApPliCATION FOR CARDiOVASCUlaR}

WHO has defined mobile health (mHealth) technology as a medical and public health practice supported by mobile devices, such as mobile phones, patient monitoring devices, personal digital assistants, and other wireless devices [6]. MHealth is using mobile technology to support health projects 
and outcomes [7]. Mobile technology has different types, such as: mobile phones/smartphones, tablets, or personal digital assistants (PDA). Keisling [7] mentions several categories of mHealth, i.e.:

- Financial transactions and incentives: this category provides services for any payments and insurances, such as: money transfer, health insurance, health payments, health incentives based on performance, and saving accounts.

- Information systems: this category supports any activities for data collection and reporting, such as: statistics, household surveys, health surveillance, electronic health records.

- Service delivery and support: this category includes any system refer to decision support system, diagnosis of certain diseases, disease management and prevention, communication between providers, referrals, and telemedicine.
- Social and behavior change communication: this category offers service such as reminders, health education, and health promotion.

- Supply management: this category involves various services such as cold chain management, commodity tracking and replenishment, and stock management.

- Workforce development and performance support: this category enables feedback for certain services such as service quality, human resource management.

Honeyman et al. [8] illustrate the potential integration and components of a generic mobile health system (figure 1). The figure shows that mobile can support and deliver healthcare in various forms, such as: voice/video calls, SMS/messages, mobile applications, multimedia, inbuilt sensors, and device connectivity. Figure 2 shows the services that can be delivered by mHealth.

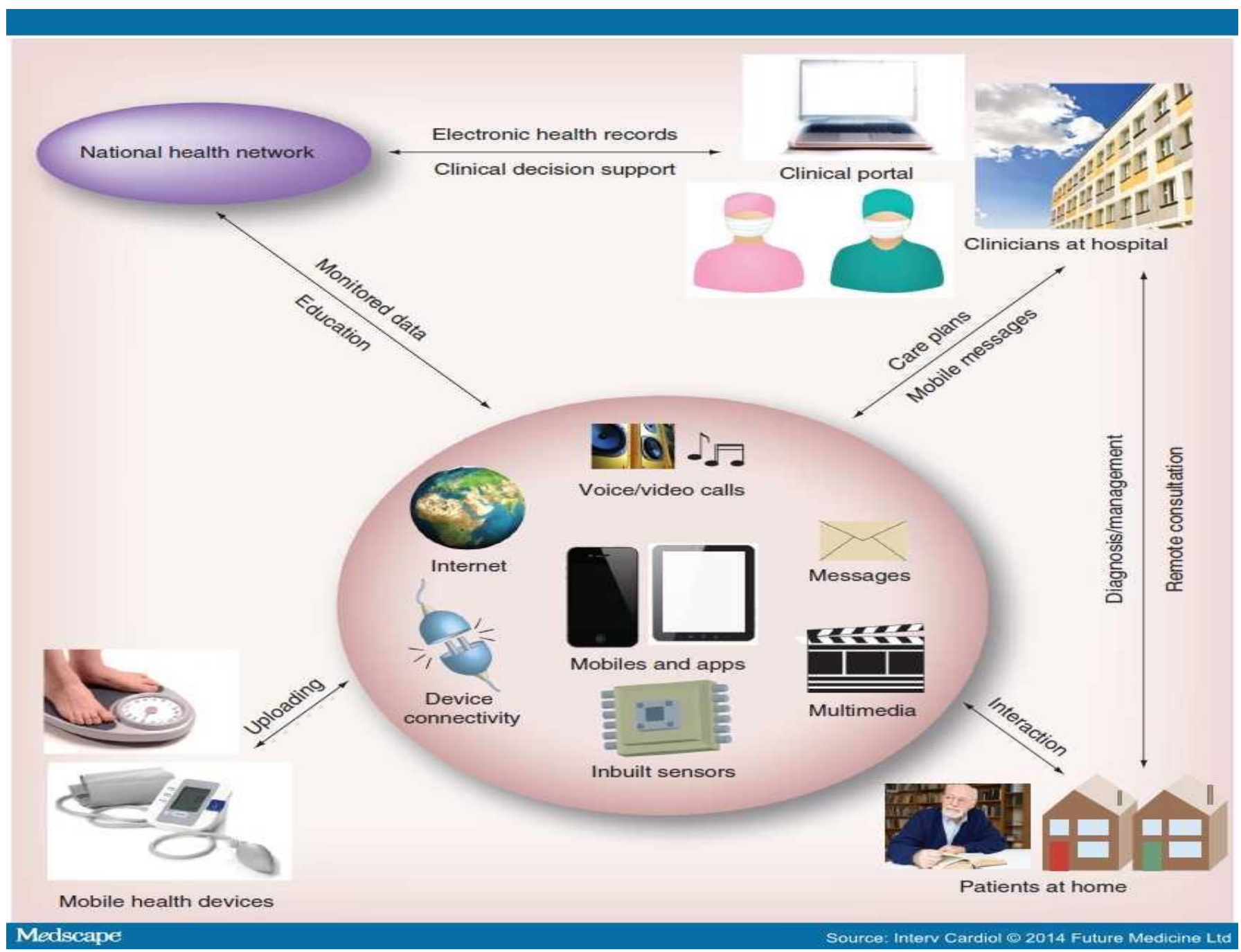

Fig. 1. The potential integration and components of a generic mobile health system [8]. 


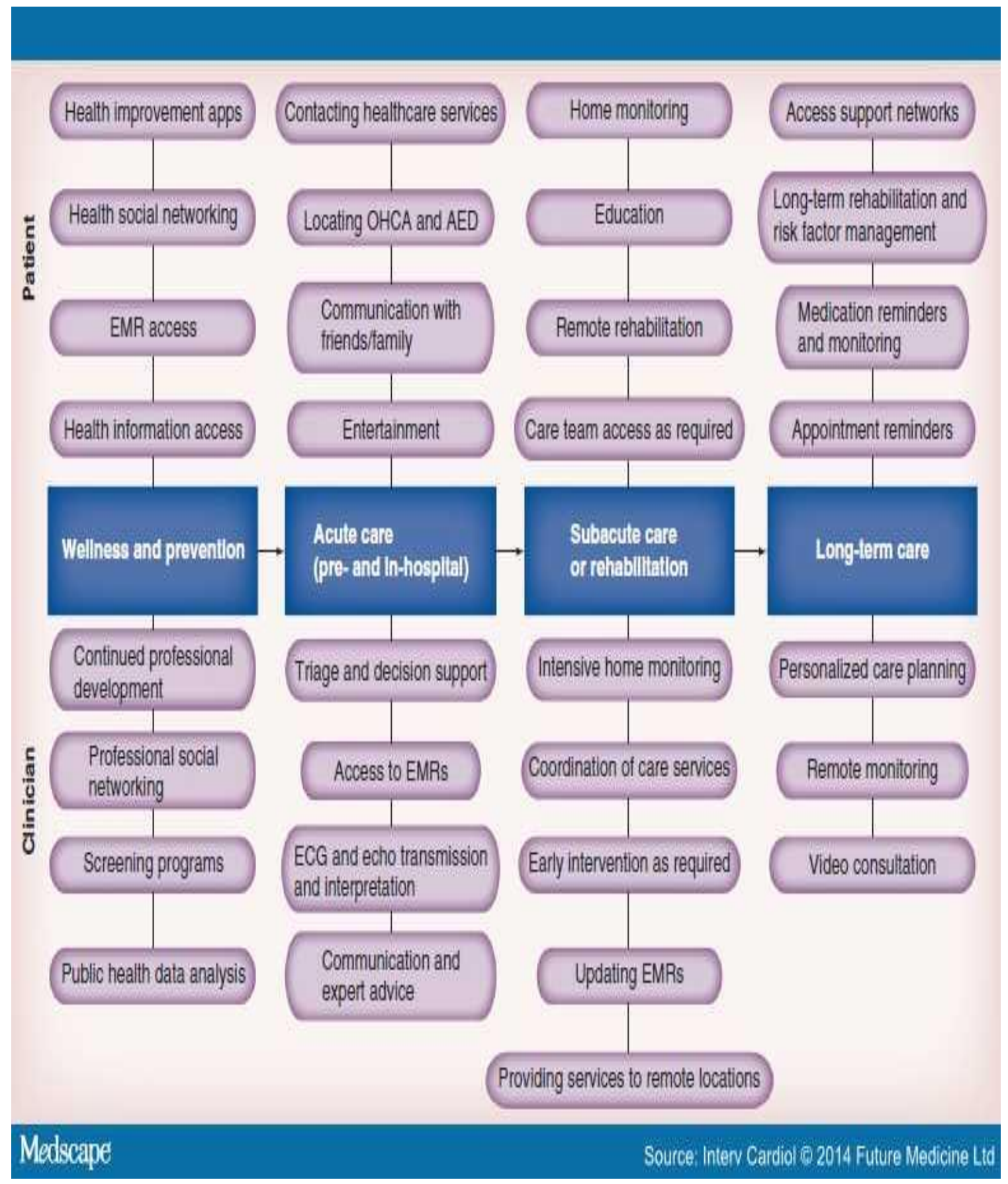

Fig. 2. Potential applications of mobile technologies by patients and clinicians at each stage of the care journey[8].

There are several research have been done to investigate the potential use of mHealth for Cardiovascular disease management $[3,4,5,7,8,9,10,11,12,13]$. The details explanations for those related research are as follows:

- Authors in [3] investigate how mHealth can control lifestyle behavior as prevention to cardiovascular diseases. In their research, Eapen et al [3] also mention that evolution of mHealth is still in the early stages, thus it requires more thorough roadmap by involving all stakeholders, such as: patients, developers, providers, and payers. By having collaboration of all stakeholders, the developers will be able to comprehend the real problem from different perspectives.

- Chow et al [4] describe the ability of mHealth as a tool for cardiovascular education and prevention, in terms of cardiac rehabilitation. However, it should be performed further investigation to ensure that mHealth is secure, safe, and robust.

- Feinberg et al [9] find out that mHealth has potential use as cardiovascular management, prevention, and 
health promotion by conducting case study in Kerala, India. The research has objectives to explore mobile phone usage pattern in rural Kerala (Ernakulam) and to explore acceptability of mHealth delivery of health promotion and cardiovascular prevention.

- Honeyman et al [8] explain detail usage of mHealth for several cardiovascular diseases, such as: cardiac arrest, arrhythmias, myocardial infarction, heart failure, and interventional cardiology. Mhealth offers significant roles to improve cardiac care from both a patient and a clinical perspective. In their research, they highlight some of the key cardiac interventions where mobile health has been applied or studied in both the acute and longer-term care settings.

- Xie et al [10] mention that mHealth can be used for promoting cardiovascular disease self-management. However in their research, they find thath Chinese cardiovascular apps are insufficient to provide comprehensive health information and interactive functions to facilitate cardiovascular self-management. They also mention that mHealth can offer efficient and affordable solution for China, since China has a large population with cardiovascular disease that requires self-management.

- Treskes et al [11] discuss several use of mHealth for remote monitoring cardiovascular patients. New technologies in smartphones have the potential to be used for remote monitoring. However, they find out some weaknesses of mHealth, such as: untrustworthiness of mobile technology, insufficient regulation and poor compensation for mHealt implementation.

- Pfaeffli et al [12] mention mHealth as promising tool as exercise tool for cardiac rehabilitation patients. The exercise is developed using mobile tool with patient input using the following steps: conceptualization, formative research, pre-testing, and pilot testing. The research find out that mHealth developed in the research was effective as an exercise program for cardiac rehabilitation patients.

- Gandapur et al [5] explain that mHealth can be used to improve medication adherence for cardiovascular disease. The aim of their research is to assess mHealth as a tool to provide better medication obedience for cardiovascular disease patients, especially patients with hypertension, coronary artery disease, heart failure, peripheral arterial disease, and stroke. Their research discovers that mHealth is able to improve medication adherence in patients with cardiovascular diseases.

- Tundjungsari et al [13] compare several mobile applications with ability to calculate cardiovascular risk factors. The aim of their research is to investigate the critical success factor of Clinical Decision Support Systems application, mainly for calculating cardiovascular risk. They conduct usability testing toward three different mHealth applications by involving participants from different types of backgrounds (physicians, IT developers, and students). The result of the research indicates that knowing the target user's needs is very critical in the design process.

Table below summarizes those literatures related to mHealth use for cardiovascular disease management.

TABLE I. RELATED RESEARCH OF MHEALTH USAGE FOR CVD MANAGEMENT

\begin{tabular}{|l|l|}
\hline Author & Research result \\
\hline Eapen et al (2016) & $\begin{array}{l}\text { mHealth as control lifestyle behaviour for CVD } \\
\text { prevention }\end{array}$ \\
\hline Chow et al (2016) & $\begin{array}{l}\text { mHealth as a tool of CVD prevention, cardiac } \\
\text { rehabilitation and education }\end{array}$ \\
\hline Feinberg et al (2017) & $\begin{array}{l}\text { Suitability and acceptability of mHealth for CVD } \\
\text { Kerala }\end{array}$ \\
\hline $\begin{array}{l}\text { Honeyman et al } \\
\text { (2014) }\end{array}$ & $\begin{array}{l}\text { mHealth as a tool of monitoring for Cardiac } \\
\text { arrest, arrhythmiac, myocardial infarction, heart } \\
\text { failure, interventional cardiology }\end{array}$ \\
\hline Xie et al (2017) & mHealth as tool for CVD self-management \\
\hline Treskes et al (2016) & mHealth as tool for remote monitoring CVD \\
\hline $\begin{array}{l}\text { Tundjungsari et al } \\
\text { Pfaeffli et al (2012) }\end{array}$ & $\begin{array}{l}\text { mHealth as a tool for calculating cardiovascular } \\
\text { intervention } \\
\text { risk }\end{array}$ \\
\hline Gandapur et al (2016) & $\begin{array}{l}\text { mHealth as tool for improving medication } \\
\text { adherence CVD }\end{array}$ \\
\hline
\end{tabular}

\section{Human CENTERED DESIGN FOR INTERACTIVE SYSTEMS}

The implementation of the system was carried out using a principle of Human or User Centered Design (HCD) for interactive systems standard [14]. This standard is used as user-centred interaction design process, also referred as 'the HCD standard'. The standard is based on 'BS EN ISO 9241210:2010 Ergonomics of human-system interaction. It consists of activities focussing on human-centred design, i.e.:

\section{1) Understand and specify context of use \\ 2) Specify user requirements \\ 3) Produce design solutions to meet these requirements \\ 4) Evaluate design against requirements}

The above stages also can be summarised as: (1) analysis, (2) specification, (3) design and (4) evaluation. The stages in the HCD standard have to be carried out iteratively, by having evaluation stage. Figure 3 shows how the HCD standard is implemented in a project. The project using HCD standard should involve the user from the beginning of the project until the last stage of development. By involving user from every 
stages of HCD standard, it will provide clear usability measurement.

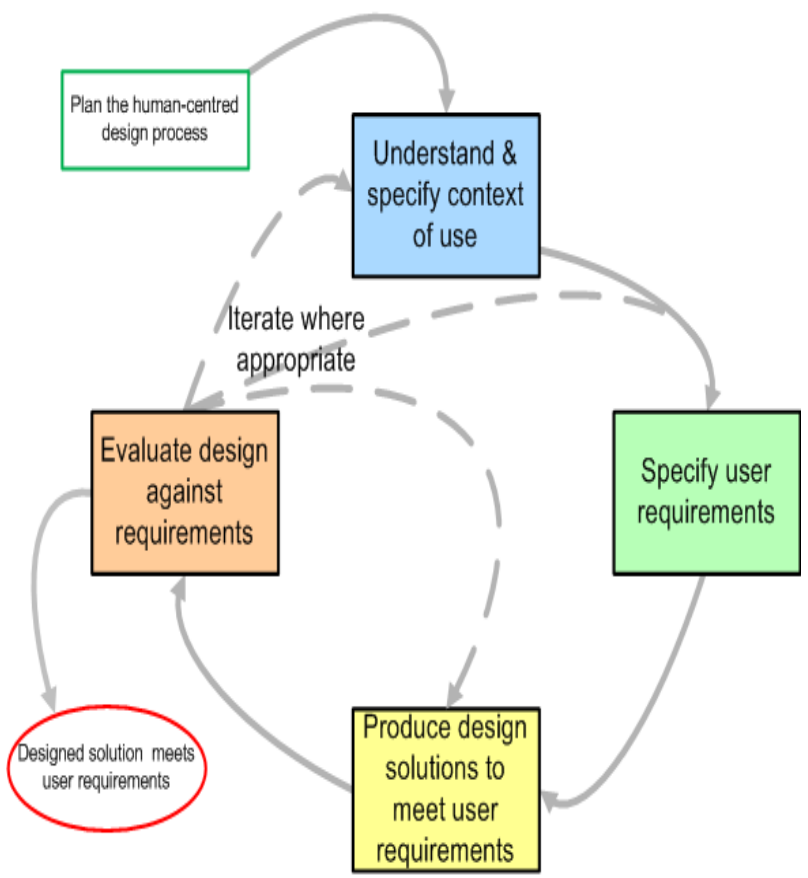

Fig. 3. Human-centered design standard [14].

In this research we perform step by step HCD standards by involving: patients, public, physicians, public health experts, developers, faculty members, and usability experts. The details of HCD process in this project is explained in table below:

TABLE II. PROCESSES AND ACTIVITIES IN HCD STANDARD

\begin{tabular}{|c|c|}
\hline Stage & Activities \\
\hline $\begin{array}{l}\text { HCD 1: Understand } \\
\text { and specify context of } \\
\text { use }\end{array}$ & $\begin{array}{ll}\text { - } & \text { Application concept } \\
\text { - } & \text { Features lists } \\
\text { - } & \text { Task Scenarios lists } \\
& \text { Finding reliable source from Minister of } \\
& \text { Health Republic of Indonesia }\end{array}$ \\
\hline $\begin{array}{l}\text { HCD 2: Specify user } \\
\text { requirements }\end{array}$ & $\begin{array}{l}\text { Requirements details for each task (task, sub-task, } \\
\text { significance, and frequency) }\end{array}$ \\
\hline $\begin{array}{l}\text { HCD 3: Produce } \\
\text { design solutions to } \\
\text { meet these } \\
\text { requirements }\end{array}$ & Low-fidelity prototype production \\
\hline $\begin{array}{l}\text { HCD 4: Evaluate } \\
\text { design against } \\
\text { requirements }\end{array}$ & $\begin{array}{l}\text { Evaluation design and high-fidelity prototype } \\
\text { production }\end{array}$ \\
\hline
\end{tabular}

IV. RESULT AND DISCUSSION

\section{A. Understand and Specify Context of use}

Application Concept: This application is a mobile based application with function to prevent cardiovascular disease by promoting healthy behavior and life style. The components of healthy behavior and lifestyle are provided from Ministry of Health Republic of Indonesia. There are six main components which determine the healthy behavior and lifestyle as prevention to cardiovascular diseases, i.e.: (1) encourages the public to carry out regular health checks, (2) eliminate cigarette smoke, (3) diligently engage in physical activity, (4) a healthy and balanced diet, (5) adequate rest and manage stress.

Based on those concepts, we propose several features to be developed in this application, i.e.:

1) Recording and calculating daily sleeping time

2) Recording daily eating time (breakfast, lunch, dinner)

3) Recording and calculating daily physical activities/exercise time

4) Recording and calculating daily amount of water consumption

5) Recording and calculating stress level

6) Recording and calculating daily number of cigarettes consumption (for smoker)

\section{B. Specify User Requirements}

Feature 1: Recording and calculating daily sleeping time

\begin{tabular}{|l|l|}
\hline Task group & Recording sleeping time \\
\hline Sub tasks & $\begin{array}{l}\text { Save sleeping time } \\
\text { Save wake up time }\end{array}$ \\
\hline Significance & $\begin{array}{l}\text { Calculate duration of sleeping time (sleeping time to } \\
\text { wake up time) }\end{array}$ \\
\hline Frequency of use & Daily \\
\hline
\end{tabular}

Feature 2: Recording and calculating daily eating time (breakfast, lunch, dinner)

\begin{tabular}{|l|l|}
\hline Task group & Recording eating time (breakfast, lunch, dinner) \\
\hline Sub tasks & $\begin{array}{l}\text { Save breakfast time } \\
\text { Save lunch time } \\
\text { Save dinner time } \\
\text { Save fruit and vegetable consumption }\end{array}$ \\
\hline Significance & $\begin{array}{l}\text { Calculate average daily eating habit (time and } \\
\text { ingredients) }\end{array}$ \\
\hline Frequency of use & Daily \\
\hline
\end{tabular}

Feature 3: Recording and calculating daily physical activities/exercise time

\begin{tabular}{|l|l|}
\hline Task group & Recording physical activity/exercise time \\
\hline Sub tasks & $\begin{array}{l}\text { Calculating daily steps done } \\
\text { Calculate daily distance steps done }\end{array}$ \\
\hline Significance & $\begin{array}{l}\text { Calculate average daily physical activity (steps and } \\
\text { distance) }\end{array}$ \\
\hline Frequency of use & Daily \\
\hline
\end{tabular}


Feature 4: Recording and calculating daily amount of water consumption

\begin{tabular}{|l|l|}
\hline Task group & Recording amount of water consumption \\
\hline Sub tasks & $\begin{array}{l}\text { Save amount of water (glasses) } \\
\text { Save caffeine consumption (if any) } \\
\text { Save alcohol consumption (if any) }\end{array}$ \\
\hline Significance & $\begin{array}{l}\text { Calculate average daily drinking habit (amount and } \\
\text { ingredients) }\end{array}$ \\
\hline Frequency of use & Daily \\
\hline
\end{tabular}

Feature 5: Recording and calculating stress level

\begin{tabular}{|l|l|}
\hline Task group & Recording stress level \\
\hline Sub tasks & $\begin{array}{l}\text { Save stress incidence (if any) } \\
\text { Save stress level (0-100) }\end{array}$ \\
\hline Significance & Calculate average daily stress level \\
\hline Frequency of use & Daily \\
\hline
\end{tabular}

Feature 6: Recording and calculating daily number of cigarettes consumption (for smoker)

\begin{tabular}{|l|l|}
\hline Task group & Recording smoking behavior \\
\hline Sub tasks & Save smoking active and passive behavior (if any) \\
\hline Significance & Calculate average daily smoking behavior \\
\hline Frequency of use & Daily \\
\hline
\end{tabular}

\section{Produce design solutions to Meet these Requirements}

The first prototype of the system was designed and produced as low-fidelity prototype, as it can be seen in figure 4. The first prototype is used to show the navigation flow and overall design based on the user requirement (stage 2 of HCD).

\section{Evaluate Design Against Requirements}

The final prototype was designed based on the feedback gathered in the previous prototypes. This final prototype is a fully functional mobile application. Some of the final prototypes are shown in figure 5, 6, 7, and 8 .

To evaluate the prototype we use User Experience Questionnaire (UEQ). UEQ is used to measure: (1) attractiveness (overall impression of the application. Do users like or dislike it?); (2) clarity (does the context of application give clarity? Does the interface element give clarity?); (3) efficiency (can users solve their tasks without unnecessary effort? Does it react fast?); (4) accuracy and dependability? (does the application provide accurate result? Does the user feel in control of the interaction? Is it secure and predictable?);

(5) stimulation (is it exciting and motivating to use the product? Is it fun to use?); (6) novelty (is the design of the product creative? Does it catch the interest of users?).

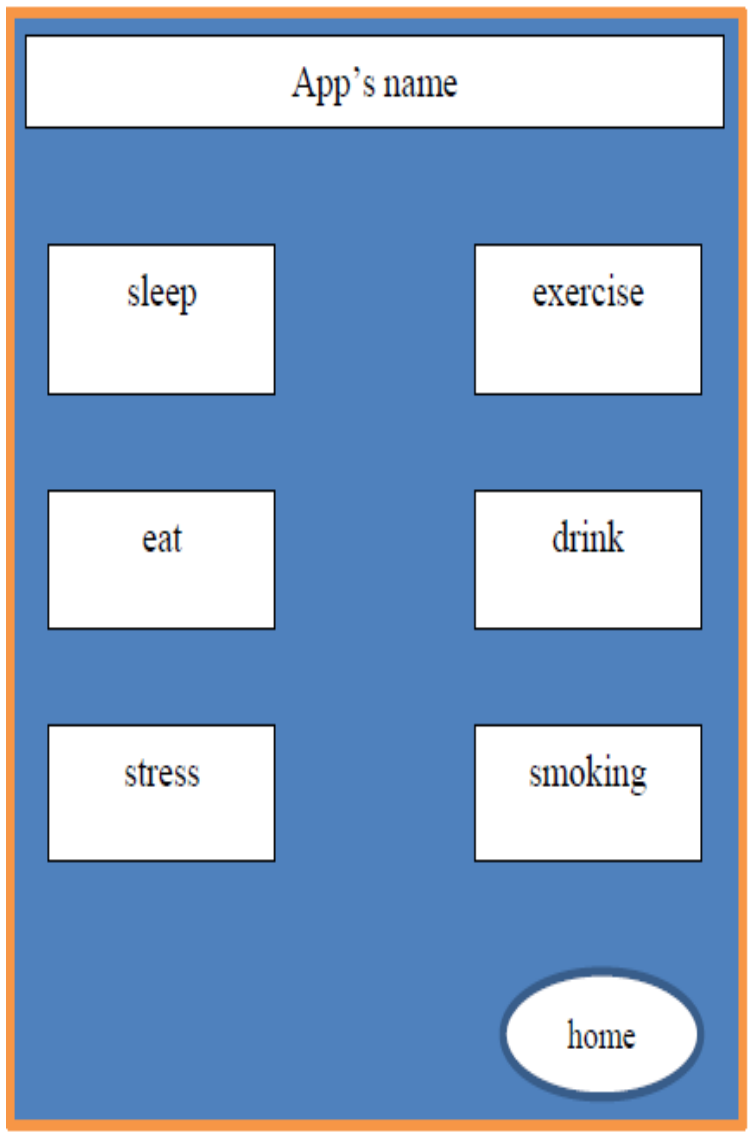

Fig. 4. Low-Fidelity Prototype.

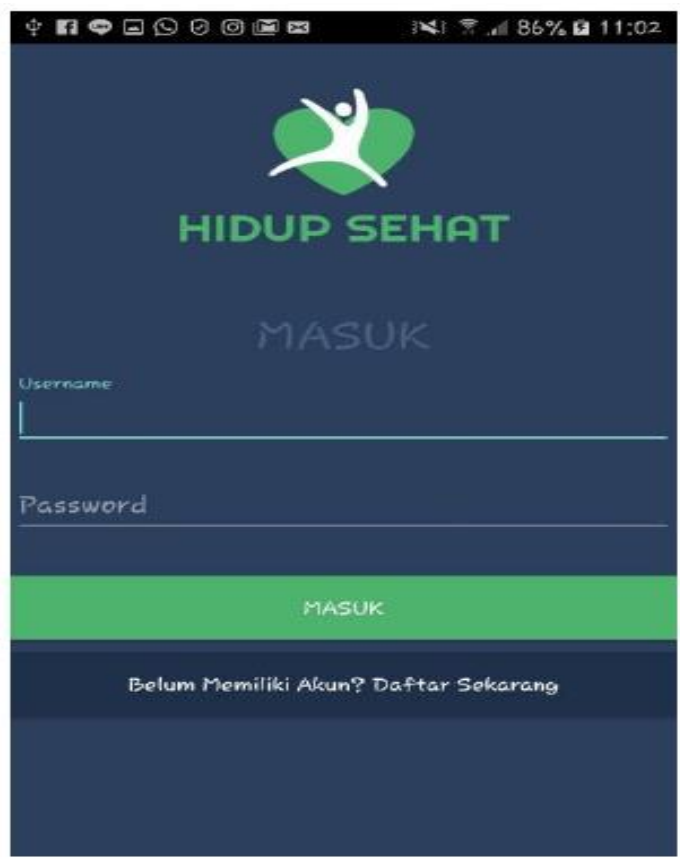

Fig. 5. Interface of Final Prototype (1). 


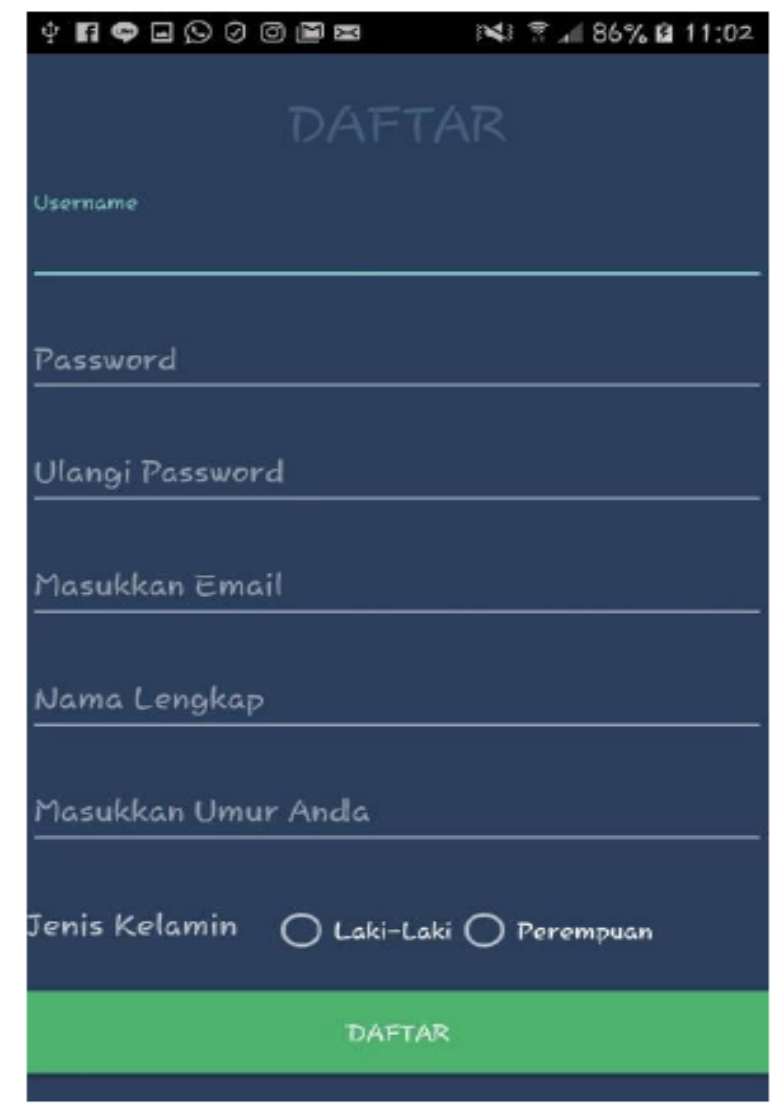

Fig. 6. Interface of final prototype (2).

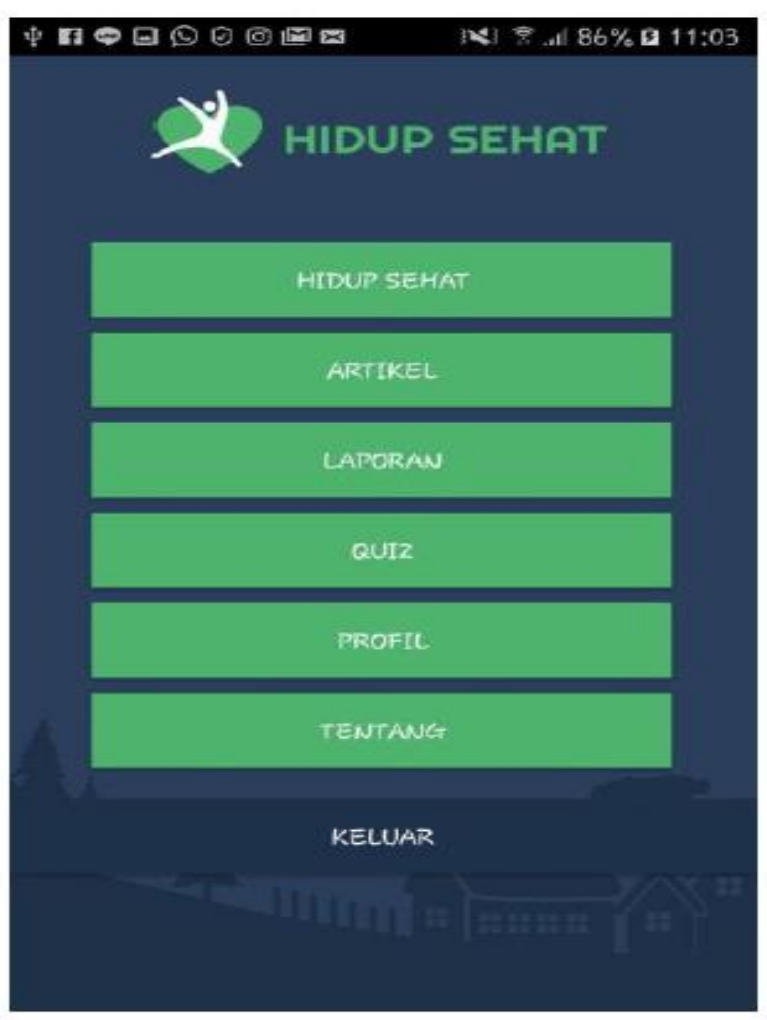

Fig. 7. Interface of final prototype (3).

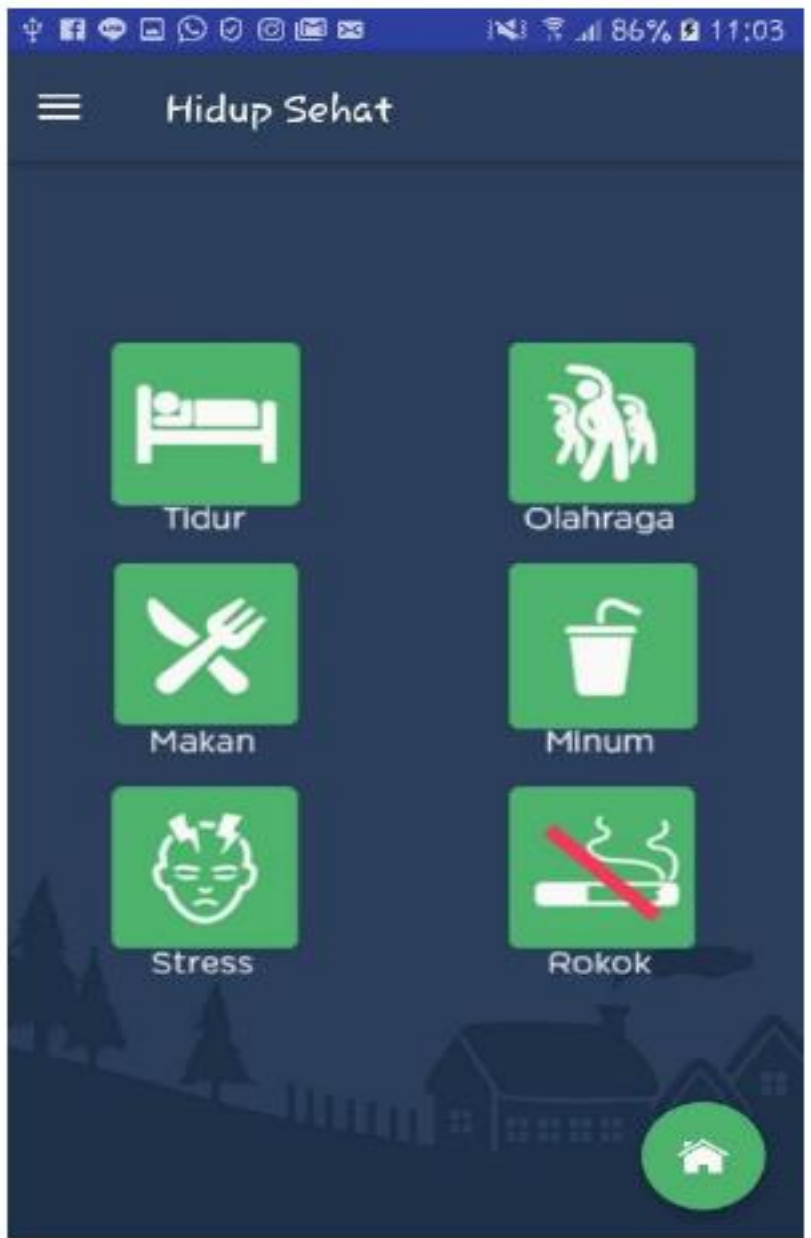

Fig. 8. Interface of final prototype (4).

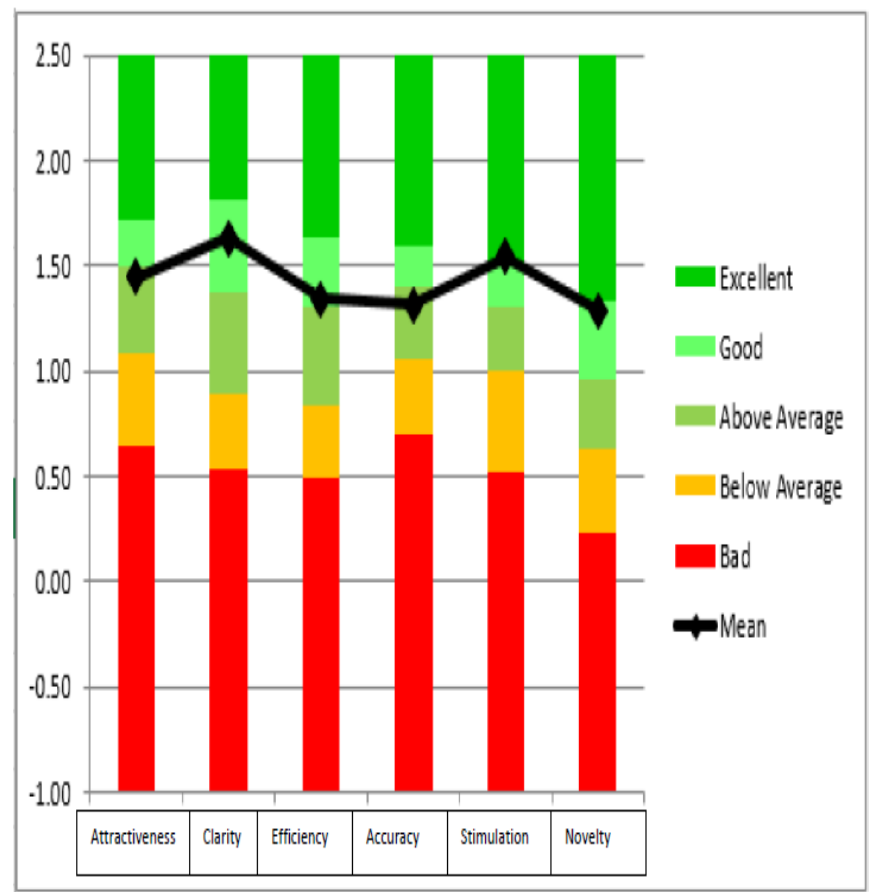

Fig. 9. Application evaluation result using UEQ. 
We evaluate the final prototype using User Experience Questionnaire (UEQ) as an instrument. There are 30 respondents with various ages (15-64 yearsold) involved in the assessment. They have to experience the mHealth application and fill in the UEQ based on their experience of using the mHealth application. Figure 9 shows the UEQ test result. The best result is achieved by component stimulation with 'excellent' score, followed by clarity with 'good' score. However the highest average score is performed by clarity component, followed by stimulation. On the other hand, the worst result is accuracy having score of 'above average'. Overall UEQ result shows that all of the components have score 'above average' which indicate that the application perform 'good' experience to users.

\section{CONCLUSION}

In this research, a development of mHealth application as a tool to promote health behaviour and life style is performed. The application is developed using stages determined by HCD for interactive systems standard. The evaluation result obtained shows that the application able to stimulate the respondent as users to use the application. This proves that mHealth is a potential tool to promote healthy behaviour and life style, and in turn as an enabler tool for preventing cardiovascular diseases. However, the accuracy result is not as high as other components. This indicates that there are still many doubts occurred from the respondents regarding the accuracy of the application. It means that we still need more approval from health and medical expert to validate the accuracy of the application.

In the future, we have to evaluate the application in real environment and involving collaboration between health care professionals and app developers, in order to achieve better end users' preferences and more accurate result.

\section{ACKNOWLEDGMENT}

This work was funded by the Ministry of Research Technology and Higher Education Republic of Indonesia, under PDUPT research schema. We would like to thank also to Universitas YARSI for its support during the research study.

\section{REFERENCES}

[1] https://www.who.int/cardiovascular_diseases/en/

[2] http://www.depkes.go.id/resources/download/general/Hasil\%20Riskesda s\%202013.pdf

[3] Z.J. Eapen, M.P. Turakhia, M.V. Mcconnell, G. Graham, P. Dunn, C. Tiner, C. Rich, R.A. Harrington, E.D. Peterson, P. Wayte, 2016,"Defining A Mobile Health Roadmap For Cardiovascular Health And Disease", Journal Am Heart Assoc, 2016 Jul, 5 (7).

[4] C.K. Chow, N. Ariyarathna, S.M. SharifulIslam, A. Thiagalingam, J. Redfern, 2016, "mHealth in Cardiovascular Health Care", Heart, Lung, and Circulation, Volume 25, Issue 8, August 2016.

[5] Y. Gandapur, S. Kianoush, H.M. Kelli, S. Misra, B. Urrea, M.J Blaha, G. Graham, F.A. Marvel, S.S. Martin, 2016, "The Role of mHealth for Improving Medication Adherence in Patients with Cardiovascular Disease: A Systematic Review”, European Heart Journal - Quality of Care and Clinical Outcomes (2016) 2, 237-244.

[6] WHO Library Cataloguing in Publication Data, 2011, mHealth: New horizons for health through mobile technologies: second global survey on eHealth.

[7] K. Keisling, 2014, Introduction to mHealth: How to Approach mHealth.mHelp org August 2014.

[8] E. Honeyman, H. Ding, M. Varnfield, M. Karunanithi, 2014, "Mobile Health Applications in Cardiac Care", Interv Cardiol 6 (2).

[9] L. Feinberg, J. Menon, R. Smith, J.G. Rajeev, R.K. Kumar, A. Banerjee, 2017, "Potential for Mobile Health (mHealth) Prevention of Cardiovascular Diseases in Kerala: A Population-based Survey", Indian Heart Journal 69 (2017) 182-199.

[10] B. Xie, Z. Su, W. Zhang, R. Cai, "Chinese Cardiovascular Disease Mobile App' Information Types, Information Quality, and Interactive Functions for Self-Management: Systematic Review", JMIR MHealth and UHealth.

[11] R.W. Treskes, E.T. Van der Velde, R. Barendse, N. Bruining, 2016, "Mobile Health in Cardiology: A Review of Currently Available Medical Apps and Equipment for Remote Monitoring", Expert Review of Medical Devices.

[12] L. Pfaeffli, R. Maddison, R. Whitaker, R. Stewart, A. Kerr, Y. Jiang, G. Kira, K. Carter, L.Dalleck, 2012, "A MHealth Cardiac Rehabilitation Exercise Intervention: Findings from Content Development Studies", BMC Cardiovascular Disorders 2012 12:36.

[13] V. Tundjungsari, A.S.M. Sofro, A. Sabiq, A. Kardiana, 2017, "Investigating Clinical Decision Support Systems Success Factors with Usability Testing", International Journal of Advanced Computer Science and Applications (IJACSA), Volume 8 Issue 11, 2017.

[14] R. Harte, L. Glynn, A. Rodríguez-Molinero, P.M. Baker, T.Scharf, L.R. Quinlan, G. ÓLaighin, 2017, "A Human-Centered Design Methodology to Enhance the Usability, Human Factors, and User Experience of Connected Health Systems: A Three-Phase Methodology", JMIR human factors, Volume 4, No 1. 